\title{
Dialoog zonder discipline. Uitdagingen in de publieksgeschiedenis
}

\author{
Marijke Huisman
}

'Wat is Geschiedenis?' Onder deze titel gaf Maria Grever het eerste hoorcollege van de Ba-1-cursus Historisch Atelier, waaraan ik in 2012-13 als docent meewerkte. Ze legde studenten eerst de twee betekenissen van 'geschiedenis' uit: alles wat gebeurd is en de verhalen over al dat gebeurde. $\mathrm{Na}$ uitweidingen over de maatschappelijke relevantie van geschiedenis en historisch besef kwam Grever bij de ontwikkeling van de geschiedwetenschap, geïllustreerd met een portret van Leopold von Ranke. De academische discipline geschiedenis karakteriseerde ze met vijf inhoudelijke kenmerken: 'betoog met feiten, bronnen en methoden, logica betoog (argumentatiedwang), debat: hoor en wederhoor (pluraliteit perspectieven) en onafhankelijkheid', om af te sluiten met 'vijf doodzonden geschiedwetenschap': '1. anachronisme; 2. determinisme; 3 . presentisme; 4. finalisme/teleologie; 5 . instrumentalisme.'

Deze inleiding in de geschiedwetenschap is niet uniek voor Grever of de Erasmus Universiteit Rotterdam. Eerstejaarsstudenten geschiedenis worden overal op soortgelijke wijze ingewijd in de regels van de historische discipline. Dat schept orde in het debat onder vakgenoten, maar in de publieksgeschiedenis tellen die regels minder of niet. In het brede scala aan geschiedbeoefening van en voor

1 Persoonlijk archief Marijke Huisman: Geprinte powerpointslides van Maria Grevers college 'Wat is Geschiedenis', september 2012. een breder publiek draait het bij uitstek om 'usable pasts'. ${ }^{2}$ Daar staan historici tussen al dan niet boze burgers, politici, erfgoedinstellingen, commerciële bedrijven en anderen die eigen belangen hebben, de regels van de historische discipline helemaal niet (er) kennen en zonder gewetenswroeging historische doodzonden begaan - of die zelfs beschouwen als deugden. Die omgangen bieden historici uiteraard weer een schat aan bronnenmateriaal voor studies naar historische cultuur, maar dat concept biedt naar mijn idee weinig houvast voor historici die zich actief in het publieke domein begeven.

In de publiekshistorische praktijk is het één ding om je te realiseren dat diverse partijen om verschillende redenen en op uiteenlopende wijzen met het verleden bezig zijn, maar dan? 'The pursuit of history always implies a dialogue on interpretations', aldus Grever en vele anderen. ${ }^{3}$ Er zijn weinig historici die niet menen dat historisch begrip ontstaat uit dialoog en/of debat. Juist daarom trainen vakhistorici middelbare-schoolleerlingen en studenten in

\footnotetext{
2 Ludmilla Jordanova, History in practice. Third edition (Londen 2019) 175.

3 Maria Grever, 'Dilemmas of common and plural history. Reflections on history education and heritage in a globalizing world' in: Mario Carretero, Mikel Asensio, María Rodríguez-Moneo (eds.), History education and the construction of national identities (Charlotte, NC, 2012) 75-91, 88 .
} 
bronnenkritiek, argumentatie, bewijsvoering en andere elementen van 'historisch redeneren'. Maar hoe voer je een constructieve dialoog zonder de gemene deler van een discipline? Dat is met name een uitdaging voor historici die zich niet boven het bredere publiek stellen, maar samen met maatschappelijke partners vorm en inhoud proberen te geven aan wat Roy Rosenzweig en David Thelen in 1998 een participatory historical culture noemden: 'a culture in which using the past could be treated as a shared human experience and opportunity for understanding, rather than a ground for division.' ${ }^{4}$ Onder publiekshistorici is dit inmiddels een breed gedragen ideaal, maar in de praktijk van shared authority belandt de historicus per definitie in een dynamiek met concurrerende opvattingen over zonden en deugden. Op basis van eigen ervaringen in een participerend publiekshistorisch project over en met de Utrechtse boekwinkel Savannah Bay belicht ik die dynamiek in de bredere historische cultuur en reflecteer ik op de (on)mogelijkheden van een dialoog zonder discipline. ${ }^{5}$

\section{Botsende belangen}

Savannah Bay is een kleine, onafhankelijke boekwinkel die zich onderscheidt met een gespecialiseerd aanbod op het gebied van gender, postkolonialisme en LGBT-thema's. Deze queer boekhandel komt voort uit De Heksenkelder, in 1975 de eerste feministische

4 Roy Rosenzweig \& David Thelen, The presence of the past. Popular uses of history in American life (New York 1998) 190.

5 Dit is mijn perceptie van het proces en mijn reflectie daarop; ik heb deze tekst niet voorgelegd aan of afgestemd met de projectpartners. De eindredacteuren van Savannah Bay blijven hier naamloos om te benadrukken dat mijn kritiek op hun rol in het proces niet over hen of de kwaliteit van hun werk gaat. boekwinkel in Nederland. Die is dan ook verbonden met de tweede feministische golf, toen activisten een ontstellend gebrek aan informatie van, voor en over vrouwen in het bestaande medialandschap signaleerden en een eigen netwerk van feministische uitgeverijen, drukkerijen en boekwinkels creëerden. In 1970 ontstonden de eerste winkels in de Verenigde Staten: Amazon in Minneapolis (Minnesota) en A Woman's Place in Oakland (Californië). Nadien volgenden er wereldwijd meer, ook in Nederland. ${ }^{6}$ De meeste verdwenen in de jaren negentig, maar De Heksenkelder bestaat nog steeds - zij het sinds 1984 onder de naam Savannah Bay.

De geschiedenis van de vrouwenboekbeweging is nog nauwelijks geschreven, terwijl dat wel de moeite waard is. In de eerste plaats is er het historisch belang om meer te weten over een van de meest invloedrijke sociale bewegingen van de twintigste eeuw. Daarnaast denk ik dat onderzoek naar de vrouwenboekbeweging meer nuance kan brengen in de historische beeldvorming over de tweede feministische golf. Sinds circa de eeuwwisseling zijn thema's als seksegelijkheid en seksuele vrijheid een centrale rol gaan spelen in debatten over de Nederlandse identiteit en de (grenzen van de) multiculturele samenleving, waardoor een beeld van de tweede golf is ontstaan als beweging van en voor seculiere, witte en heteroseksuele vrouwen. Die beeldvorming is nog versterkt door een nieuwe generatie 'intersectioneel feministen' die zich met oog voor de kruisverbanden tussen sekse, seksualiteit en ras of kleur zeggen te onderscheiden van voorgangers. Dat doet in mijn optiek weinig recht

6 Marijke Huisman, 'Feministische Uitgeverij Sara (1976-1987). Case-studie voor een inclusieve geschiedenis van de tweede feministische golf in Nederland', Historica 39:3 (2016) 18-23; Marijke Huisman e.a., Savannah Bay. Geschiedenis van een bijzondere boekwinkel, 1975-2019 (Utrecht 2019) 14-17. 


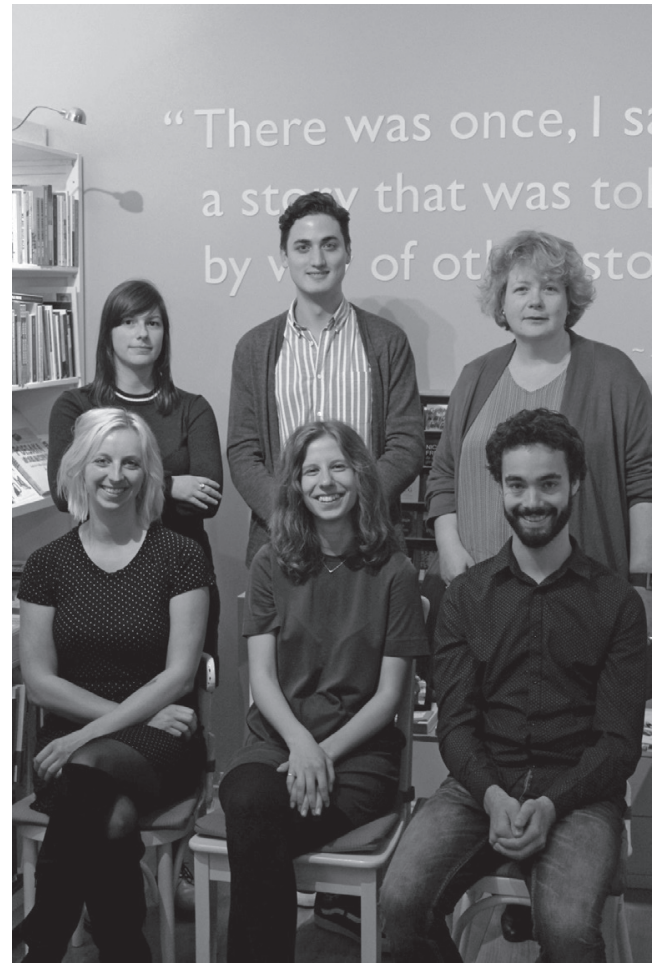

Het boekteam, van linksboven naar rechtsonder (staand) Onessa Novak, Lex van Rens, Marijke Huisman; (zittend) Suzanne van der Beek, Suzanne Balm, Timo Houtekamer. Foto: Jantine Broek.

aan de historische tweede golf en ik wilde dat beeld bijstellen. De vrouwenboekbeweging leek mij een geschikt startpunt, omdat ik wist dat lesbiennes hier de toon zetten, er relatief veel vrouwen van kleur actief waren en de feministische boekproductie zicht bood op de breedte van de toenmalige vrouwenbeweging - inclusief discussies over de samenhang tussen verschillende vormen van discriminatie. ${ }^{7}$

In de zomer van 2018 had ik nog slechts vage plannen voor een lange-termijnonderzoek naar de vrouwenboekbeweging in $\mathrm{Ne}$ derland, maar bij een bezoek aan Savannah Bay informeerde ik of de winkel een archief

7 Kristen Hogan, The feminist bookstore movement. Lesbian antiracism and feminist accountability (DurhamLondon 2016). had en dat eens mocht inzien. Eigenares Marischka Verbeek was direct enthousiast over mijn ideeën, mede omdat Savannah Bay in 2019 haar 35-jarig jubileum zou vieren en een winkelgeschiedenis daar goed bij zou passen. We besloten tot samenwerking en formeerden een 'boekteam'. Naast mij zelf, universitair docent geschiedenis aan de Universiteit Utrecht, bestond dat uit vijf leden: drie recent afgestudeerde studenten geschiedenis, Timo Houtekamer, Onessa Novak en Lex van Rens, van wie één (Houtekamer) als vrijwilliger in Savannah Bay werkte; Suzanne van der Beek, universitair docent cultuurwetenschappen aan de Universiteit Tilburg, tevens vrijwilliger in de winkel, en studente Taal- en Cultuurstudies Suzanne Balm die stage kwam lopen in Savannah Bay en het boekteam. In februari 2019 begonnen we met het onderzoek en in november werd onze geschiedenis van Savannah Bay gepresenteerd tijdens een jubileumfestival in TivoliVredenburg. Ik ben trots op dit resultaat, maar de weg was bezaaid met hobbels die de uitdagingen van publieksgeschiedenis goed illustreren.

Een eerste uitdaging lag op het terrein van de onafhankelijkheid, want daarvan was in dit project geen sprake. Het hele team bestond uit mensen die zijn verbonden met de winkel, als vrijwilliger, klant en/of donateur. Verbeek financierde de productie van het door Savannah Bay uit te geven boek en samen met haar formuleerde het boekteam de inhoudelijke opzet. Zij gaf ons daarbij de ruimte, maar op een cruciaal punt waren wij zeer afhankelijk van onze maatschappelijke partner: de bronnen. ${ }^{8}$ Het Utrechts Archief had niets over De Heksenkelder/Savannah

8 Dit is niet uniek voor ons project, zie de verdwijning van archiefbronnen in een project over de geschiedenis van Bristol: Madge Dresser, 'Politics, populism, and professionalism: Reflections on the role of the academic historian in the production of public history', The Public Historian 32:3 (2010) 39-63. 
Bay. Het specialistische Internationaal Archief van de Vrouwenbeweging in Atria (Amsterdam) had wel een aantal dozen over De Heksenkelder, bijbehorend café De Heksenketel en de beginjaren van Savannah Bay, maar de bulk van ons onderzoeksmateriaal lag, en ligt, in het kantoor achter de winkel, in ongeorganiseerde mappen, dozen en digitale dropboxen. Een deel van de geschiedenis stond helemaal niet op papier of in een digitaal bestand en bestaat slechts nog in de hoofden van ex-vrijwilligers en medewerkers. Gecombineerd met ons participatiehistorische streven de mensen in en rondom de winkel een stem in onze geschiedschrijving te geven, verzamelden wij daarom herinneringen tijdens een speciale bijeenkomst en hielden we interviews.

Een van onze belangrijkste informatiebronnen was Verbeek zelf, omdat zij al sinds het einde van de jaren tachtig bij de winkel is betrokken - eerst als vrijwilliger, begin jaren negentig als betaalde medewerker en vanaf 1997 als zelfstandig ondernemer/eigenaar van Savannah Bay. Dezelfde Verbeek moest ons toegang geven tot het winkelarchief en de contactinformatie van oud-medewerkers. Het papieren en digitale archief stelde zij ruimhartig voor ons open; we konden alles zien wat we wilden. Bij de selectie van te interviewen personen bleken er echter grenzen te bestaan. Verbeek wilde niet dat we Lenneke de Ruijter zouden interviewen, een vrouw die vanaf 2013 betaalde winkelmanager was en in 2016-17 namens Savannah Bay in het boekenpanel van tv-programma De Wereld Draait Door zat. In de zomer van 2018 had De Ruijter ontslag genomen. Niemand van ons wist daar het fijne van, maar het was duidelijk dat dit afscheid niet harmonieus was verlopen. Verbeek verwees ons naar de andere betaalde medewerker uit diezelfde periode. In het boekteam hebben we deze kwestie besproken. Sommigen vonden dat wij als onafhankelijke historici juist met De Ruijter moesten spreken, maar dat hebben we niet gedaan. Praktische zaken als tijd speelden een rol, maar natuurlijk ook de relatie met Verbeek. Inhoudelijk waren we bovendien van mening geen gesprek met De Ruijter nodig te hebben voor de geschiedenis die wij over Savannah Bay wilden vertellen. Op basis van het (digitale) archief konden we genoeg vinden over haar bijdrage aan de recente winkelgeschiedenis. Ze is ook zichtbaar in het beeldmateriaal, maar lezers die bekend zijn met Savannah Bay zullen haar relatieve afwezigheid in de tekst vermoedelijk opmerken.

Een tweede uitdaging vormden de verschillende belangen. Ik was op een missie om het historische beeld over de tweede golf bij te stellen, zoals ik schreef. Op dat punt vonden Verbeek en ik elkaar, maar daar speelden andere belangen doorheen. Zo zag ik dit project óók als kans ervaring op te doen met een vorm van participerende publieksgeschiedenis waarvan ik in theorie veel weet, maar die ik nooit had gepraktiseerd. In die zin is het tijdens de rit bijgehouden logboek mijn belangrijkste projectresultaat. De jongere teamleden waren vooral op zoek naar een stage dan wel historische werkervaring. Suzanne van der Beek zag haar onderzoek voor ons boek als startpunt voor een groter project - net zoals ik, maar over een ander onderwerp. Verbeek had nog weer andere belangen. Vanaf het moment dat ik naar het archief vroeg, sprak zij over het boek als 'tastbare legacy'. Zij was persoonlijk sterk bezig met vragen over haar bijdrage aan de geschiedenis van Savannah Bay en de toekomst van deze kleine, onafhankelijke boekwinkel. In haar gedaante als ondernemer zag zij het boek, het festival en de overige jubileumactiviteiten als manieren om publiciteit te genereren en daardoor de overlevingskansen van de winkel te vergroten. Tegelijkertijd maakte ze zich als ondernemer 
grote zorgen over de financiering van het jubileum, waardoor de lees- en daarmee verkoopbaarheid van het boek misschien wel haar grootste belangen waren.

Tijdens het proces heb ik de retoriek over legacy en leesbaarheid wel gehoord, maar me achteraf bezien niet goed gerealiseerd welke consequenties die voor onze geschiedschrijving kon hebben. Die werden meer dan duidelijk in de zomer van 2019, toen de uit twee Savannah Bay-vrijwilligers bestaande eindredactie ons manuscript op verzoek van Verbeek had gelezen en een totale herschrijving voorstelde of eiste - daarover verschillen de meningen. Een deel van de kritiek ging over te formeel of academisch taalgebruik en de koppenstructuur, eenvoudig te veranderen dingen. Problematischer waren de in mijn ogen regelrecht anti-historische commentaren van de jonge literatuurwetenschappers.

In de eerste plaats schrapten de eindredacteuren grote stukken tekst die 'te historisch' waren, wat in hun ogen gelijk stond aan 'saai', 'technisch', 'niet interessant' en 'niet relevant'. Zij maakten deze opmerkingen opvallend vaak bij passages die niet direct gingen over boekwinkel De Heksenkelder of Savannah Bay, maar over de sociale, politieke en culturele context rondom de winkel. Zo kon een stuk over het ontstaan van landelijk, provinciaal en stedelijk emancipatiebeleid volgens de eindredacteuren beter verdwijnen. Op andere punten wilden ze juist meer weten, bijvoorbeeld over hoe lang de liefdesrelatie tussen de twee lesbische oprichtsters van De Heksenkelder duurde en waarom die eindigde. Dit soort vragen gingen voor mij over futiele human-interestdetails in de microwereld van Savannah Bay, terwijl het emancipatiebeleid voor mij uiterst relevant was omdat daarmee samenhangende subsidies vrouwenboekhandels mede mogelijk maakten. En ik was bezig uit te zoomen naar een grotere geschiedenis over de tweede golf waarin deze ene boekhandel een casus was. De eindredactionele commentaren maakten echter duidelijk dat er nogal verschillende gedachten leefden over wat er wel of niet toe deed in een geschiedenis van Savannah Bay/De Heksenkelder.

Dit had mij niet hoeven verrassen. Op basis van honderden interviews met burgers constateerden Rosenzweig en Thelen al dat het brede publiek de macrogeschiedenis in bijvoorbeeld schoolboeken als 'saai' of 'abstract' kwalificeert en relatief veel waarde hecht aan nabije geschiedenis, het verleden van de eigen buurt of regio, de eigen familie of sociale groep. Zo bezien spreken leken en vakhistorici een geheel andere taal over het verleden. Daaronder ligt volgens Rosenzweig en Thelen een botsing tussen 'people ethics' en 'historian ethics'. De door hen geïnterviewden spraken namelijk over het verleden in termen van identiteit, continuïteit en morele levenslessen, terwijl professionele historici vaak proberen het andere of vreemde in context te zetten en zo genuanceerd mogelijk over het voetlicht te brengen. Maar, zoals Rosenzweig en Thelen het onderkoeld formuleerden: 'morality is not a category that has lately figured in our professional discourse, where relativist notions prevail'. ${ }^{9}$ In de vrije, ongedisciplineerde wereld van publieksgeschiedenis strijden partijen daarentegen open en bloot om de macht hun moraal van een geschiedverhaal dominant te maken - zo blijkt momenteel uit discussies over (on)gewenste representaties van het koloniale en slavernijverleden in schoolboeken of musea. ${ }^{10}$ Professionele

9 Rosenzweig \& Thelen, The presence of the past, 184. 10 Anton Froeyman, 'The ideal of objectivity and the public role of the historian. Some lessons from the Historikerstreit and the History Wars', Rethinking History 20:2 (2016) 217-234; Marijke Huisman, 'Er missen kanten. Multiperspectiviteit in erfgoededucatie over slavernij', Cultuur + Educatie 19:55 (2020) 111-127. 
historici staan uiteraard niet buiten de discussies van hun tijd, maar de hele discipline is erop gericht de moraliteit van de historicus te temperen of ten minste transparant te maken door middel van vakhistorische spelregels.

Hoe weinig die voor anderen kunnen tellen, bleek uit de tweede soort commentaren van de eindredactie. Die raakten voor mij aan Grevers historische doodzonde 3: presentisme. Stukken over de relatief oude geschiedenis van De Heksenkelder werden veel vaker geschrapt dan tekstpassages over het hedendaagse Savannah Bay, de winkel en de mensen die de eindredacteuren uit eigen ervaring kennen. Zij gebruikten bovendien een hedendaagse morele meetlat voor de beoordeling van het verleden, waardoor een door mij geschreven passage met een citaat uit circa 1975 problematisch werd. Daarin behandelde ik een document van de lezingengroep van De Heksenkelder, die destijds door de stad trok om scholieren en burgers in buurthuizen en andere instellingen informatie te geven over de geschiedenis van feminisme en de vrouwenbeweging. In het document, een schematisch handvat voor sprekers, werd de eerste feministische golf kort samengevat, waarna de opkomst van de tweede golf werd verklaard. Dat leidde in het manuscript tot deze zin van mijn hand, met hier cursief gezet het gewraakte citaat:

De tweede feministische golf begon in deze lezing tussen 1960-1965, toen vrouwen die participeerden in de nieuwe sociale bewegingen voor 'de rechten van:negers, studenten, homofielen, opleving van arbeidersbeweging etc.' zich realiseerden 'dat er ook met hun rechten nog wel het één en ander mis was'.

Zelf vond en vind ik het citaat relevant voor het thema van het hoofdstuk waarin het

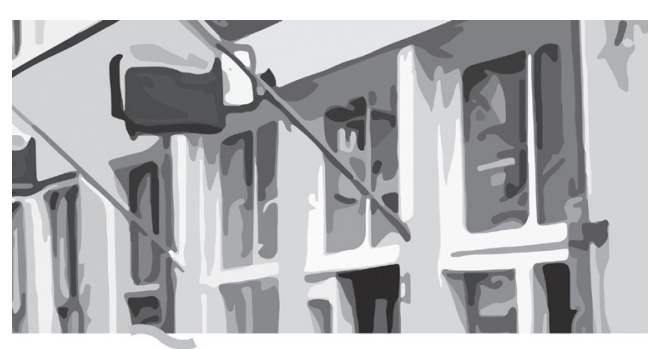

SAVANNAH BAY

GESCHIEDENIS VAN EEN BIJZONDERE BOEKWINKEL 1975-2019

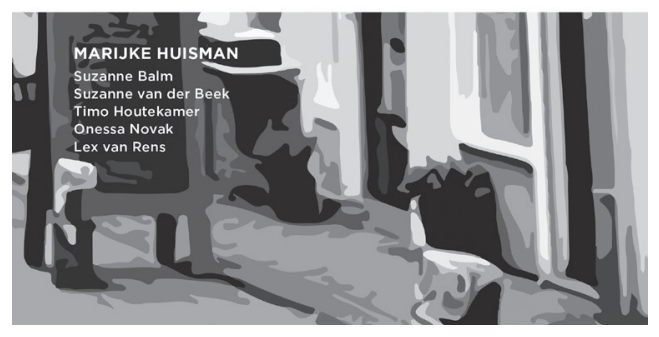

Omslag en vormgeving van het boek over Savannah Bay, door Miriam van de Ven

verscheen: de rol van vrouwenboekwinkels in de opbouw van een feministische historische cultuur en het academisch specialisme vrouwen/gendergeschiedenis. Het citaat toont hoe vrouwen van toen hun beweging definieerden, en dan is het volgens mij interessant om te zien dat zij die in relatie tot onder andere de homo- en burgerrechtenbeweging zagen. In de rest van het hoofdstuk en boek betogen we immers dat sekse, seksualiteit en ras of kleur ook tijdens de tweede golf in samenhang werden gezien - in ieder geval in de vrouwenboekwinkel. We tonen daarbij dat de verbanden en prioriteiten in de loop der tijd anders zijn gelegd, oude termen verdwenen en nieuwe opkwamen. Zo bezien vind ik het citaat zelfs uiterst relevant, maar de eindredacteuren en Verbeek wilden absoluut niet geassocieerd worden met voorgangers die 'homofielen' en, vooral, het 'n-woord' gebruikten. Het citaat moest weg. 


\section{Tact \& assertiviteit}

Ik stond perplex. Maandenlang hadden we afgestemd met Verbeek, maar nu werden we ineens geconfronteerd met inhoudelijk commentaar van een partij die nooit eerder bij het proces was betrokken. Medio juni hielden we een samen met Verbeek geplande vergadering voor de inhoudelijke bespreking van alle concept-hoofdstukken, maar de altijd drukke ondernemer had die laten passeren en de eindredacteuren waren evenmin aangehaakt. Het was inmiddels eind juli, maar Verbeek had nog steeds geen tijd gevonden ons manuscript te lezen. Zij vertrouwde daarentegen blind op het oordeel van de eindredacteuren, naar mijn idee omdat de jonge vrijwilligers het potentiële koperspubliek zouden representeren. Er moest herschreven worden, en snel; de kopij moest al bijna naar de vormgever. Dat werk dreigde bij mij terecht te komen omdat de rest van het boekteam op vakantie was. Maar ruim na de gezamenlijk bepaalde deadlines was ik niet genegen nóg meer tijd in dit project te steken, zeker niet om een van historische context en onwelgevallige citaten gezuiverde 'usable past' voor de Savannah Bay-partners te leveren. Mijn woede over de gang van zaken was zodanig dat ik zelfs heb overwogen mijn (overgrote) deel van de kopij terug te trekken - en daarmee het hele boek om zeep te helpen. Het resultaat was een crisis.

Mijn gedragslijn correspondeerde niet bepaald met aanbevelingen uit de literatuur over participerende publieksgeschiedenis, waarin juist de waarde van een dialoog wordt benadrukt. In theorie stond (en sta) ik daar volledig achter, vandaar mijn keuze voor een dergelijk project en de afstemming tussen boekteam en Verbeek in een voor mijn gevoel eindeloze serie vergaderingen. Uit de theorie wist ik ook al wel dat het voeren van een constructieve dialoog niet gemakkelijk is en veel tijd vergt, bijvoorbeeld om een brug te slaan tussen verschillende belangen en manieren van spreken over het verleden. Studies over dialogisch geschiedenisonderwijs tonen bovendien dat leerlingen niet altijd bereid of in staat zijn te luisteren en zich te verplaatsen in andermans perspectieven. ${ }^{11}$ In de onderwijscontext heeft de historicus als docent echter de macht de spelregels te bepalen en daarmee het dialogische proces te sturen en regisseren. Juist die macht had ik in dit participerende project niet en toen het er op aankwam ging het daadwerkelijk delen van gezag mij overduidelijk matig af, maar ik was niet de enige. De goedwillende eindredacteuren werden vermalen in een machtsstrijd tussen mij en Verbeek.

Een op historisch verstaan gerichte dialoog kan niet bestaan zonder 'tact', aldus Maria Grever in haar meest recente boek met reflecties op historische cultuur. In een tijd van felle strijd tussen mensen die hun perspectief op bijvoorbeeld 'het' Nederlandse verleden als waarheid willen opdringen aan anderen, pleit zij voor 'tact' - opgevat als een bedachtzaamheid en fijngevoeligheid die ruimte voor verschillen laat en juist daardoor mogelijk tot nieuwe inzichten of ten minste een horizonverbreding leidt. ${ }^{12}$ Een dergelijke tact kon ik eind juli 2019 niet opbrengen; in de slotfase van ons dialogische project was ik niet bereid te luisteren naar een voor mij nieuw naar voren geschoven gesprekspartner: de eindredacteuren. Daar kwam bij dat hun opmerkingen mij zwaar tegen de historische borst stuitten. Dat we

\footnotetext{
11 Grever, 'Dilemmas of common and plural history', $81-87$.

12 Maria Grever, 'Ontkoombaar verleden. Over historisch verstaan en tact' in: Idem, Onontkoombaar verleden. Reflecties op een veranderende historische cultuur (Hilversum 2020) 160-172
} 
toch weer op dezelfde golflengte zijn beland, is te danken aan de tact van Verbeek.

Die bleek begin augustus in een door haar belegde crisisvergadering met mij en stagiaire Suzanne Balm namens het boekteam, een van de eindredacteuren en Verbeek zelf. Zij nam de leiding en begon de vergadering met een rondje. Ieder kreeg ruimte de ontstane situatie vanuit eigen perspectief te belichten. Deze aanpak klaarde de lucht en bevorderde het inlevingsvermogen in elkaars posities en belangen. Pas daarna bespraken we of en hoe we verder konden, en wat daarvoor nodig was. Zelf was ik na anderhalve week enigszins gekalmeerd en tot het inzicht gekomen dat het zo ver in het proces zonde zou zijn al het gedane werk, ook van de andere teamleden, teniet te doen door uit het project te stappen. Ik zei daarom bereid te zijn nog één werkweek aan de bewerking van het manuscript te spenderen, maar eiste tegelijkertijd totale en definitieve zeggenschap over het boek. Na mijn herziening kon er zonder mijn medeweten geen letter meer veranderd worden.

Terugblikkend geloof ik niet dat 'tact' de lading van mijn gedrag tijdens deze vergadering dekt. Een beter woord lijkt mij 'assertiviteit', in dit geval op te vatten als zelfverzekerd opkomen voor mijn belangen als professioneel historicus met ideeën over historische zonden en deugden. Daartussen zit wat mij betreft wel speelruimte, zeker op het terrein van de publieksgeschiedenis. Tegelijkertijd heeft dit participerende project mij duidelijk gemaakt dat er in de dialogische samenwerking met maatschappelijke partners ook grenzen zijn, zowel in het proces als het eindproduct. De 'saaie' contextinformatie is dus gebleven, ofschoon ik bij de herschrijving heb geprobeerd de relevantie voor de winkelgeschiedenis beter duidelijk te maken. Het 'n-woord' was zo'n fundamenteel probleem voor de Savannah Bay-partners dat ik daar water bij de wijn heb gedaan door het citaat te parafraseren. Of dat tactvol of zondig is, moeten anderen maar uitmaken.

\section{Over de auteur}

Dr. Marijke Huisman is sinds 2018 universitair docent Public History, Education \& Civic Engagement bij het departement Geschiedenis en Kunstgeschiedenis van de Universiteit Utrecht. In 2020 deed zij een zakelijker vormgegeven contractonderzoek over de geschiedenis van Centraal Boekhuis, 1871-2021.

E-mail:m.h.huisman@uu.nl 